\title{
A quantitative study of $\alpha$-naphthyl acetate esterase-positive cells in non-Hodgkin's lymphomas and reactive lymph nodes
}

\author{
J CROCKER, EL JONES, RC CURRAN
}

From the Department of Pathology, The Medical School, University of Birmingham, Birmingham B15 2TJ

SUMMARY The numbers of $\alpha$-naphthyl acetate esterase (ANAE)-containing cells (other than T lymphocytes) in non-Hodgkin's lymphomas (NHL) and reactive lymph nodes have been counted, using the Reichert-Jung (Kontron) $\mathrm{MOP}-\mathrm{AMO}_{3}$ user-controlled image analyzer. Twenty specimens of NHL and ten reactive nodes were examined. Cells were demonstrated by their content of acid $\alpha$-naphthyl acetate esterase (ANAE) in fixed frozen sections. It was found that lymphomas of high-grade malignancy contained much larger numbers of ANAE-positive cells (10.8-20.5\%) than those of low-grade malignancy $(1.4-4 \cdot 1 \%)$. The number of ANAE-positive cells $(1.4$ $3.2 \%$ ) in reactive lymph nodes was similar to that in low-grade NHL nodes.

Non-Hodgkin's lymphomas always contain $\alpha$-naphthyl acetate esterase-positive cells (including macrophages) which can be identified in sections by the use of enzyme histochemical markers. ${ }^{1}$ The functional significance of macrophages is uncertain however; they may form part of a response to the malignant lymphoid tissue. True histiocytic lymphomas are presumed to be derived from neoplastic histiocytes.

It has been shown that high grade lymphomas give a higher yield of glass-adherent cells (presumably including macrophages) than low grade NHL. ${ }^{2}$ We have counted ANAE-positive cells in NHL and reactive lymph nodes by means of the Reichert-Jung (Kontron) MOP-AMO $\mathrm{AM}_{3}$ user-controlled image analyzer. With this instrument cells can be counted rapidly and accurately. ${ }^{3}$ Enzyme-positive cells were demonstrated in sections by the acid $\alpha$-naphthyl acetate esterase (ANAE) technique. ${ }^{4}$ The majority of cells demonstrated by this means are of the macrophage type (either rounded or branching) although dendritic reticulum cells, which are very weakly positive for ANAE, are presumably also included.

\section{Material and methods}

LYMPH NODES

Thirty lymph nodes were examined, from the same number of patients. Ten specimens were of low-

Accepted for publication 16 March 1982 grade NHL, 10 were of high-grade NHL and 10 were reactive lymph nodes (Table). The reactive nodes were from patients either with a demonstrable infection or showed reactive changes of unknown aetiology.

\section{FIXATION, PROCESSING, AND ENZYME} HISTOCHEMISTRY

The lymph nodes were collected from the operating theatre directly after surgery. They were cut into 2 mm thick slices with a degreased razor blade and fixed in cold $\left(4^{\circ} \mathrm{C}\right)$ formol-calcium and subsequently transferred to gum-sucrose solution. Frozen sections were cut on a cryostat at $6 \mu \mathrm{m}$ and stained for ANAE as previously described. ${ }^{4}$ Slices were also fixed in $10 \%$ formol-saline at room temperature and dehydrated and embedded in paraffin wax. Sections were cut at 2-3 $\mu \mathrm{m}$ and stained by Harris's haematoxylin and eosin for diagnostic histology.

Specimens counted and percentage of ANAE-positive cells present

\begin{tabular}{|c|c|c|c|}
\hline \multicolumn{2}{|l|}{ Diagnosis } & $\begin{array}{l}\text { No of } \\
\text { specimens }\end{array}$ & $\begin{array}{l}\text { \% of ANAE- } \\
\text { positive cells }\end{array}$ \\
\hline \multicolumn{2}{|c|}{ Reactive lymnh nodes } & 10 & $1.4-3.2$ \\
\hline $\begin{array}{l}\text { Low grade } \\
\text { NHL }\end{array}$ & $\begin{array}{l}\text { Centrocytic } \\
\text { 'entrocytic- }\end{array}$ & 3 & $1.4-1.8$ \\
\hline $\mathbf{N}$ & $\begin{array}{l}\text { centroblastic } \\
\text { Centroblastic }\end{array}$ & $\begin{array}{l}7 \\
2\end{array}$ & $\begin{array}{l}1 \cdot 5-4 \cdot 1 \\
14 \cdot 6 \text { and } 17 \cdot 5\end{array}$ \\
\hline $\begin{array}{l}\text { High grade } \\
\text { NHL }\end{array}$ & $\begin{array}{l}\text { Immunoblastic } \\
\text { Lymphoblastic } \\
\text { Unclassifiable }\end{array}$ & $\begin{array}{l}6 \\
1 \\
1\end{array}$ & $\begin{array}{l}12 \cdot 8-20 \cdot 5 \\
10 \cdot 8 \\
19\end{array}$ \\
\hline
\end{tabular}


The specimens of NHL were classified according to the Kiel convention. ${ }^{1}$

\section{CELL COUNTING PROCEDURE}

The ANAE-containing cells in sections from each of the lymph nodes were counted as previously described in detail, ${ }^{3}$ by means of the Reichert-Jung (Kontron) MOP-AMO ${ }_{3}$ user-controlled (interactive) image analyzer. Five-hundred lymphoid cells were counted and stored on one channel of the machine. The numbers of ANAE-positive cells were then counted for the same fields and stored on another channel. At the end of the counting procedure the microprocessor printed out the data and expressed the number of ANAE-positive cells as a percentage of the total cell count. A simple eyepiece graticule was used to prevent cells being counted more than once. T-lymphocytes, which contain one or two punctate areas of ANAEpositivity, ${ }^{45}$ were readily differentiated from macrophages and dendritic reticulum cells for the purposes of the total count.

For each specimen counted, a note was made on a further channel of the MOP-AMO $\mathrm{A}_{3}$ of the numbers of fields examined for the total cell count of 500 cells. The counts were performed using a $\times 40$ objective lens. Fields were selected randomly.

In the case of follicular types of NHL and nodes showing follicular hyperplasia, the cell count was performed in such a way that both follicular and interfollicular areas were included in equal proportions.

\section{Results}

Enzyme-positive cells were well-defined and stained strongly by the ANAE technique, enabling rapid and easy enumeration with the aid of the MOP$\mathrm{AMO}_{3}$. In lymphoid tissue, cells containing this enzyme in multiple granules and diffusely in their cytoplasm were of two varieties. Firstly, large rounded cells including "tingible-body" macrophages and secondly branching macrophages with several long enzyme-containing cytoplasmic processes. ${ }^{467}$ The latter are to be distinguished from socalled true dendritic cells, which lack acid phosphatase and are weakly positive for ANAE, possess a high surface membrane concentration of 5'nucleotidase but like macrophages are glassadherent. $^{4}$

As the Figure shows, the ANAE-positive cell content was much greater in high-grade NHL (range $10 \cdot 8-20.5 \%$ of total cells) than in low-grade NHL (range $1 \cdot 4-4 \cdot 1 \%$ of total cells). Reactive lymph nodes contained a similar number of positive cells $(1 \cdot 4-3 \cdot 2 \%)$ to low-grade NHL. No significant dif-

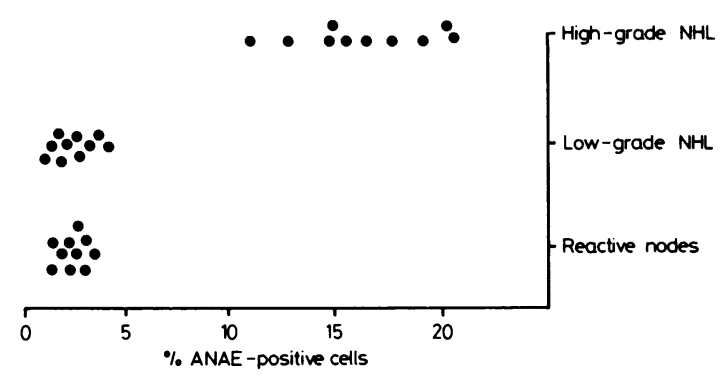

The percentage of ANAE-positive cells in high-and low-grade $N H L$ and in reactive lymph nodes.

ference was seen between the positive cell content of the various subtypes of high-grade NHL. The same was true for the subtypes of low-grade NHL.

Two $\times 40$ objective fields were sufficient to include the entire 500 cells in some specimens, whereas in other specimens as many as six $\times 40$ fields were necessary.

\section{Discussion}

Macrophages are a well-recognised component of malignant lymphomas of both the Hodgkin and non-Hodgkin types. ${ }^{1}$ In most instances they are assumed to be non-neoplastic and are of a similar appearance to those seen in reactive lymph nodes and palatine tonsils. ${ }^{4}$ However their role in lymphomatous tissue is obscure; they could be part of a host-defence mounted against the lymphoma or could merely represent remnants of a previously normal or reactive lymph node.

As we have previously shown with regard to immunoglobulin-containing cells in bone marrow trephine specimens the Reichert-Jung (Kontron) MOP- $\mathrm{AMO}_{3}$ user-controlled image analyzer provides a rapid and convenient means of counting large numbers of cells. ${ }^{3}$ It can store the numbers of different cell types on separate channels. The macrophage content of NHL tissue lymph nodes has been quantified by Katz; in this study, cell suspensions were made and the percentage of glassadherent cells calculated. Our findings are in general agreement with those of Katz; however we have used a more direct method by counting the number of ANAE-positive cells and expressing them as a percentage of the total cell count. True dendritic reticulum cells are glass-adherent and, as they are weakly ANAE-positive, ${ }^{1}$ cells of this type are included in our counts, although most of the positive cells are macrophages. It is necessary to perform an absolute cell count, since the cellularity of our specimens varied, as can be seen from the number of 
high-power fields ( 2 to 6 ) occupied by 500 cells in different specimens. Therefore counting the number of enzyme positive cells per high power field would not accurately reflect the absolute positive cell content.

The findings that all high-grade lymphomas contain a considerably greater number of ANAEpositive macrophages and dendritic cells than do low-grade NHL and reactive nodes is of interest. In the past, large numbers of "tingible-body" and other macrophages in conventional tissue sections (stained by haematoxylin and eosin) have been used as a criterion for the diagnosis of reactive lymph nodes. ${ }^{8}$ In contrast, "tingible-body" macrophages constitute the "starry-sky" appearance seen in lymphoblastic or Burkitt-type lymphomas, which are of high-grade malignancy.' The "starry-sky" appearance is not, however, now generally regarded as pathognomonic of lymphoblastic lymphoma. ${ }^{9}$ If one assumes that reactive macrophages are mounting a partly successful defence against the lymphoma, it might be expected that their numbers would be greater in low-grade NHL. Conversely, however, it could be that the high-grade specimens in some way stimulate a greater attempted (but failed) attack by macrophages. There may be several reasons for the different numbers of macrophages in the high- and low-grade NHL. It is possible that low-grade NHL grows more slowly and "sneaks through" the macrophage defence system and that the high macrophage content of high-grade NHL is related to its faster growth-rate or greater cell necrosis.

The demonstration that up to approximately $20 \%$ of the cells in high-grade NHL are ANAE-positive cells (which are mostly macrophages) also illustrate: the caution with which a diagnosis (on enzyme histochemical grounds) of true histiocytic lymphomas must be made. The striking appearance of these cells when stained for ANAE activity may lead to falsely exaggerated subjective impressions of their numbers in lymphomas.

We wish to thank Mrs Mary Williams for her expert technical assistance and Miss Angela Wright for typing the manuscript. This work was supported by grants from the Endowment Fund Medical Research Committee of the Central Birmingham Health District and The Royal Society.

\section{References}

' Lennert K. Malignant lymphomas other than Hodgkin's disease. New York: Springer-Verlag, 1978.

${ }^{2}$ Katz DR. Macrophages in non-Hodgkin lymphomas and hairy cell leukaemia. J Pathol 1981;134:117-32.

${ }^{3}$ Crocker J, Curran RC. A quantitative study of the immunoglobulin-containing cells in trephine samples of bone marrow. J Clin Pathol 1981;34:1080-2.

${ }^{4}$ Crocker J. The enzyme histochemistry of lymphoid and nonlymphoid cells of the human palatine tonsil: a basis for the study of lymphomas. J Pathol 1981;134:81-95.

${ }^{5}$ Mueller J, Brun del Re G, Buerki H, Keller H-U, Hess MW, Cottier H. Non-specific acid esterase activity: a criterion for differentiation of $\mathrm{T}$ and $\mathrm{B}$ lymphocytes in mouse lymph nodes Eur J Immunol 1975;5:270-4.

- Dorfman RF. Enzyme histochemistry of normal, hyperplastic and neoplastic lymphoreticular tissues. In: Symposium on lymphoid tumours in Africa. Basel/New York: S Karger 1963;304-26.

${ }^{7}$ Li CY, Yam LT, Crosby WH. Histochemical characterisation of cellular and structural elements of the human spleen. $J$ Histochem Cytochem 1972;20:1049-58.

${ }^{8}$ Rappaport $\mathrm{H}$. Tumours of the hematopoietic system. Atlas of tumour pathology, Section III, Fascicle 8. Washington DC: Armed Forces Institute of Pathology, 1966;426-31.

${ }^{4}$ Henry K. Bennett MH. Farrer-Brown G. Classification of the non-Hodgkin's lymphomas. In: Recent advances in histopathology No 10. Edinburgh, London and New York: Churchill Livingstone. 1978:288-9.

Requests for reprints to: Dr J Crocker, Department of Pathology, The Medical School, University of Birmingham, Birmingham B15 2TJ, England. 